\title{
Metabolic Costs of Aggressive Behaviour in the Siamese Fighting Fish, Betta splendens
}

\author{
Nídia Castro ${ }^{1}$, Albert F.H. Ros ${ }^{1 *}$, Klaus Becker ${ }^{2}$, and Rui F. Oliveira ${ }^{1}$ \\ ${ }^{1}$ Unidade de Investigação em Eco-Etologia, Instituto Superior de Psicologia Aplicada, Rua Jardim do Tabaco 34, \\ Lisboa, Portugal \\ ${ }^{2}$ Department of Aquaculture Systems and Animal Nutrition in the Tropics and Subtropics, University of Hohenheim
}

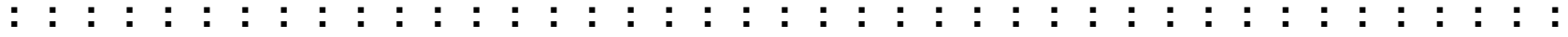

Aggressive conflicts between males are often resolved by means of multiple ritualized agonistic displays without damaging escalation. Apparently, in such cases by using those displays opponents exchange important motivational and physical information on which they base a decision to stay or leave the interaction. In the Siamese fighting fish, the time spent spreading the dorsal fin and erecting the gill coverts predicts who will be the winner or loser of the interaction. Two experiments were carried out to study whether display performance might be costly. First, oxygen consumption was measured during mirror-image stimulation. This experiment showed that oxygen consumption was positively correlated with gill cover erection and dorsal fin spread. In the second experiment, a fight between two opponents was simulated and the oxygen consumption of the expected winner and loser was compared. Metabolic rates were not different between winners and losers before and during the fight, but winners showed higher oxygen consumption in the night after the fight. These results are in accordance with costs of display performance and with longlasting physiological consequences of winning or losing a fight. Aggr. Behav. 32:474-480, 2006. (C) 2006 Wiley-Liss, Inc.

Keywords: aggression; oxygen consumption; Betta splendens; costs; winner-loser effect; communication

\section{INTRODUCTION}

In aggressive interactions, male competitors exhibit a ritualized sequence of signal behaviours, also called displays, during which they exchange information about their readiness and ability to fight [Baerends and Baerends-van-Roon, 1950; Enquist et al., 1990; Huntingford et al., 2000; Parker, 1974]. Both competitors are thought to profit from showing such displays by resolving the conflict without costly escalated fighting [e.g. Caryl, 1979; Maan et al., 2001; Neat et al., 1998; Zahavi, 1977]. An important condition for the evolution of display behaviour in the context of intra-sexual competition is that they are costly to produce [e.g. MaynardSmith, 1982; but see Számado, 2003]. Without such costs, animals of low condition could cheat by using displays that signal higher fighting ability than they are able to sustain, and thereby the display would ultimately lose its signal value in communication [Grafen, 1990; Zahavi, 1977]. Analyses of costs are therefore important in order to understand the evolution of communication. First analyses of the costs of fights have shown increased metabolic rates, depletion of energy reserves, and damage, emphasizing the high metabolic costs of escalated fighting [Bradbury and Vehrencamp, 1998; Grantner and Taborsky, 1998; Neat et al., 1998].

Male Siamese fighting fish, Betta splendens, aggressively defend a territory during which they use multiple highly stereotyped and conspicuous visual displays [Simpson, 1968]. Communication on visual display behaviour has been substantiated in experiments by showing that males eavesdrop on a fight and use this information in subsequent conflicts with the fighting subjects [McGregor et al., 2001; Oliveira et al., 1998]. Halperin et al. [1998] tested the costs of cheating about fighting ability by

Grant sponsor: Portuguese Foundation for Science and Technology-FCT; Grant number: POCTI/BSE/38484/01; Grant sponsor: Plurianual Program of FCT; Grant number: R\&D Unit 331/94.

*Correspondence to: A. Ros, Unidade de Investigação em EcoEtologia, Instituto Superior de Psicologia Aplicada, Rua Jardim do Tabaco 34, 1149-041 Lisboa, Portugal. E-mail: aros@ispa.pt

Received 15 December 2004; Accepted 8 June 2005

Published online 18 July 2006 in Wiley InterScience (www.interscience.wiley.com). DOI: 10.1002/ab.20147 
experimentally increasing the aggressiveness of their subjects. This was done by priming isolated males prior to testing with exposing them to their mirror image. In a staged fight with none primed males, these males had a lower attack latency and displayed more vigorously, although they were of similar body size. Halperin et al. [1998] showed that this mismatch between behavioural output and fighting potential did not pay off since they got exhausted which allowed their opponents to win the conflict. This further suggests that endurance in aggressive encounters is costly in $B$. splendens, which is in concordance with studies showing that differences in the time spent spreading the dorsal fin and erecting the gill covers predicts who will win a dyad [Evans, 1985; Simpson, 1968].

The aim of this study was to measure the interaction between metabolic costs, agonistic behaviour, and social interactions in B. splendens. Two experiments were carried out to analyse the energetic costs of fighting: In the first experiment the cost of escalating fighting was measured by confronting the fish with their mirror image. Mirror-image stimulation experimentally confronts the tested animal with an opponent on its territory that is symmetric in size, motivation, and behavioural output, therefore forming a constant aggressive reinforcement for the tested animal [e.g. Gallup, 1968; Thompson, 1966]. Probably, since in a normal confrontation with a conspecific no such strict continuity in reciprocity exists, the readiness to show aggressive display to a mirror image has been found to be somewhat higher to a mirror-image than to a conspecific [Dore et al., 1978]. Notwithstanding this difference, mirror image stimulation has been repeatedly used as a model for fighting in B. splendens [Johnson and Johnson, 1973; Meliska and Meliska, 1980; Simpson, 1968]. We used this standardized test to analyse how an increase in agonistic behaviour correlates with routine metabolic rates (RR). In the second experiment we analysed differences in metabolic rates between winners and losers.

\section{METHODS}

\section{Subjects}

B. splendens males of the red colour morph were purchased from a local dealer and individually kept in 1.51 aquaria at the animal housing facilities of the Instituto Superior de Psicologia Aplicada, in Lisbon, Portugal. Water in the aquaria was refreshed once a week and kept at a temperature of $26^{\circ} \mathrm{C}$ (range $\pm 1^{\circ} \mathrm{C}$ ). The photoperiod regime was
13L:11D. Food was supplied (Tropical Flake, Astra) at 2 days intervals.

\section{Indirect Calorimetric System and Oxygen Registration}

We used indirect calometry to study energy metabolism. The system was designed to measure oxygen concentrations from up to eight respiration chambers at constant intervals. $B$. splendens belongs to the group of labyrinth fish, and ingests a bubble of air to maintain buoyancy during swimming. We therefore left a layer of $0.5 \mathrm{~cm}$ of air in the respiration chambers. We did not measure oxygen levels in this layer, but since the chamber is a closed system with only a water inlet and outlet, oxygen concentration in the layer of air will reach osmotic equilibrium with that in the water column. Thus oxygen consumption measured from water should reflect total oxygen consumption by the fish in the respiration chambers. Respiration chambers were made from acrylic plastic. Chambers in experiment I contained 2.61 water (inside dimensions $13 \mathrm{~cm}$ wide $\times 13 \mathrm{~cm}$ high $\times 17 \mathrm{~cm}$ long) and in experiment II contained 2.11 water (inside dimensions $11 \mathrm{~cm}$ wide $\times 12 \mathrm{~cm}$ high $\times 17 \mathrm{~cm}$ long).

Water was continuously circulated to an upper water basin where it was filtered over charcoal (Eheim, Germany) and aerated with an air stone. Water kept at a temperature of $26^{\circ} \mathrm{C}$ (range $\pm 1{ }^{\circ} \mathrm{C}$, air conditioning) was distributed to the respiration chambers from a constant level in the water basin by gravity. The flow of water entering each chamber was restricted to about $25 \mathrm{ml} / \mathrm{min}$. Flow rates remained constant for weeks.

Automated continuous flow sampling $(n=8$ separate channels) allowed the rate of oxygen consumption to be measured at set intervals. Water leaving each chamber flowed via electronically operated solenoid valves to either a sensor $\left(\mathrm{CellOx}{ }^{\circledR}\right.$ fitted with stirrer type R2 300 in a flow through cell type D201, and attached to a dissolved oxygen meter Oxi 197; WTW GmbH, Germany) for measuring routine metabolism, or to a lower basin from which it was pumped back to the upper water basin.

The signal from the oxygen meter was logged by a computer for further analyses. Since the tubes leading to the oxygen meter contained water originating from the preceding measurement, we allowed for a wash-out time of $3^{\prime} 45^{\prime \prime}$ before logging the measurement received from the oxygen metre to the computer. During most time of the experiments, the software was programmed to log a measurement 
of every channel, resulting per subject in one measurement every $30 \mathrm{~min}$. During the mirror experiments only two boxes were measured and the wash-out time was set at $2 \mathrm{~min}$, resulting in one measurement every $4 \mathrm{~min}$.

\section{Experimental Design}

In order to standardize measurements, 7 days before the start of the experimental procedures, males were socially isolated in aquaria, which were separated by opaque partitions. At day one of the experiments, males were placed individually in respiration chambers, separated by opaque partitions, and were allowed to acclimatize to the new conditions for at least $16 \mathrm{hr}$ before presenting social stimuli. The following two experiments were carried out (see Fig. 1):

(I) Mirror-image stimulation experiment: This experiment was carried out to assess the relationship between agonistic behaviour and activity routine metabolism. Measurements were taken from 17 males and every male was submitted to each of the following procedures in which behaviour and respiration were measured simultaneously: (1) $10 \mathrm{~min}$ of isolation followed by $30 \mathrm{~min}$ exposure to its mirror image by placing a mirror on the side of the respiration chamber; (2) $10 \mathrm{~min}$ of isolation followed by $30 \mathrm{~min}$ exposure to a control stimulus which consisted of placing a transparent piece of glass of the same size as the mirror, on the side of the respiration chamber. In case the mirror was presented in the morning, the glass was presented in the afternoon and vice versa. During the experiments, routine metabolism was measured at $5 \mathrm{~min}$ intervals.

(II) Winner-loser experiment. To measure whether winning an interaction is costly, measurements were taken from eight dyads. In the morning of the second day after being placed in the respiration chambers, the opaque partition between two chambers was lifted and males were allowed to interact during the rest of the day. One of the dyads was discarded from the analyses because the behavioural data did not show a clear difference between the individuals (see below).

\section{Behavioural Observations and Analyses}

Behavioural observations were carried out continuously during the $30 \mathrm{~min}$ of mirror-image stimulation. In the winner-loser experiment (II), behavioural observations of $10 \mathrm{~min}$ were carried out immediately after removing the partition between the respiration chambers), 2 and $4 \mathrm{hr}$ later.

Behavioural observations were carried out from behind a black curtain using a Palm top (Palm, Inc., CA, USA) with the Fit-System ( ${ }^{\odot}$ J. Held, Switzerland) software installed. Scan sampling was carried out with a sampling period of $10 \mathrm{sec}$. Behavioural categories were based on the descriptions given by
(A)

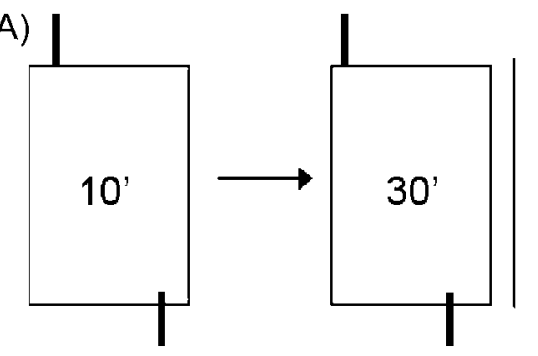

(B)

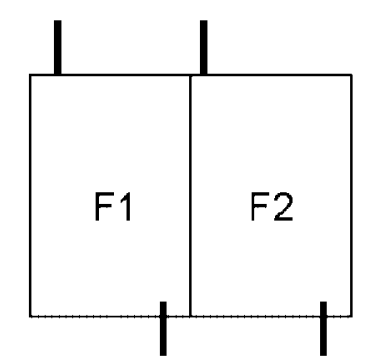

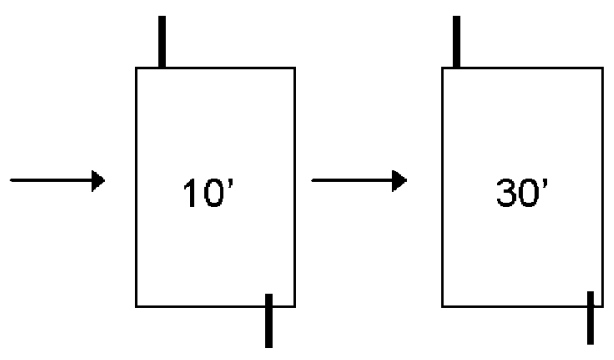

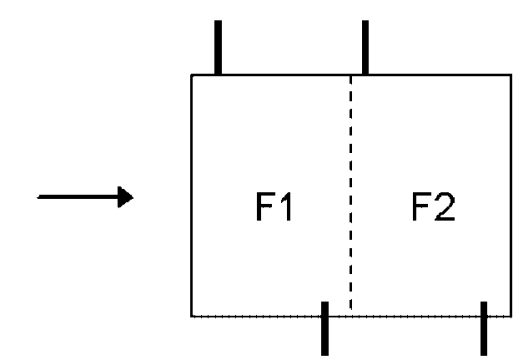

Fig. 1. Set-up of the experiments: In both experiments oxygen consumption was measured before and during the test; in the mirror-image stimulation test (A) males first were tested with their mirror image and subsequently were tested with a neutral stimulus and vice versa. 
Simpson [1968]. As agonistic behaviour the following four, not mutually exclusive, motor patterns were registered: (1) biting, a marked biting movement directed to the opponent or to the side of the chamber; (2) tail beating display, a sudden movement of the caudal fin directed towards the opponent or the side of the chamber, which is normally performed in a lateral orientation relative to the opponent; (3) dorsal spread display, erection of the dorsal fin; and (4) gill cover erection, erection of the gill covers.

Biting and tail beating display were registered as "events" and the frequency/min of these events were calculated. Dorsal spread display, gill cover erection, and non-agonistic behaviours were registered as "states" and the proportion of sampled time spent in those behaviours was calculated. Total agonistic behaviour was calculated as the time subjects spent showing any of the above-described displays as a proportion of the total time of the interaction.

Direct fights of male $B$. splendens may lead to serious damage of one of the males and even to death. Since the time males of this species spent with gill covers erected has been shown to be a good predictor of behavioural dominance [Evans, 1985; Simpson, 1968], we used relative differences in this behaviour between males in the winner-loser context as criteria to determine who was the winner and who was the loser of the interaction [McGregor et al., 2001; Oliveira et al., 1998].

\section{Calculation of Routine Metabolism}

RR were calculated using the Fick principle [see Cech, 1990] by multiplying the difference in oxygen concentration between the in and outlet of the respiration chamber with the flow of water passing through the box, and expressed as $\mathrm{mg} \mathrm{O}_{2} / \mathrm{h}$. Due to hanging water in the large ventral and dorsal fins these fish had, body mass measurements showed a large error and low repeatability (the error was about $10 \%$ ). We did not correct RR for body mass because variation in body mass between the sampled males was about similar to the measurement error. For reference, mean body mass for the animals in our batch was $1.9 \pm 0.1 \mathrm{~g}$ (mean \pm s.e.).

All oxygen measurements were carried out on post-absorptive individuals (experimental day 8) and refer to RR since no continuous activity measurements were carried out [Cech, 1990]. The following metabolic rates were calculated: (1) We calculated running averages of two consecutive measurements of oxygen consumption rate for each subject and discarded all values in which two values had more than $10 \%$ difference. From these values, the minimum value was selected (lowest routine metabolic rate, LRR); the activity routine metabolic rate was calculated as the mean metabolic rate before and during mirror stimulation in the first experiment, and as the average metabolic rate during the social stimulation in the second experiment.

\section{Statistical Analysis}

We tested data for normality by means of Kolgomorov-Smirnov and none of the distributions were significantly deviating from the normal distribution (all $P$-values $>0.10$ ), and therefore parametric statistics were applied (Pearson correlations and $t$-tests). All statistics were calculated using the SPSS 11.0 package (SPSS Inc., Chicago, USA). Two-sided $P$ values were used. Alpha was set to 0.05. Data are given as means and standard errors.

\section{RESULTS}

\section{Experiment I: Mirror-image Stimulation Test}

Males showed, although at low frequencies, agonistic displays before the neutral stimuli or mirror image was presented (Table I, about 14\% of time). This activity possibly was directed to some reflection that could be detected in the black partitions used to separate respiration boxes. No change in agonistic behaviour was detected during exposure to the neutral stimulus, whereas all

TABLE I. Effect of Exposure to a Mirror Image on Aggressive Behaviour and Oxygen Consumption in Betta splendens

\begin{tabular}{|c|c|c|c|c|c|c|c|}
\hline & \multirow[b]{2}{*}{$n=17$} & \multicolumn{2}{|c|}{ Neutral stimulus } & \multicolumn{2}{|c|}{ Mirror-image stimulus (MIS) } & \multirow{2}{*}{$\begin{array}{c}\text { Repeated ANOVA } \\
\text { df }=3 / 48\end{array}$} & \multirow{2}{*}{$\begin{array}{c}\text { Pearson } \\
\text { RR during MIS }\end{array}$} \\
\hline & & Before & During & Before & During & & \\
\hline Biting & Freq/min. & $0.02 \pm 0.02 \mathrm{a}$ & $0.02 \pm 0.01 \mathrm{a}$ & $0.06 \pm 0.05 \mathrm{a}$ & $0.88 \pm 0.14 b$ & $F=53.2, P<0.001$ & $r=0.21, \mathrm{~ns}$ \\
\hline Tail beat & Freq/min. & $0.02 \pm 0.02 \mathrm{a}$ & $0.02 \pm 0.01 \mathrm{a}$ & $0.03 \pm 0.03 \mathrm{a}$ & $0.64 \pm 0.14 b$ & $F=24.0, P<0.001$ & $r=0.60, P<0.05$ \\
\hline Dorsal spread & Time $\%$ & $13.0 \pm 5.4 \mathrm{a}$ & $19.8 \pm 6.6 a$ & $6.9 \pm 3.5 \mathrm{a}$ & $67.8 \pm 6.4 b$ & $F=31.5, P<0.001$ & $r=0.69, P<0.01$ \\
\hline Gill cover erection & Time $\%$ & $11.7 \pm 4.5 \mathrm{a}$ & $14.9 \pm 5.4 \mathrm{a}$ & $8.0 \pm 3.6 \mathrm{a}$ & $56.0 \pm 6.7 b$ & $F=27.9, P<0.001$ & $r=0.65, P<0.01$ \\
\hline Total agonistic & Time $\%$ & $16.1 \pm 6.0 \mathrm{a}$ & $17.8 \pm 5.8 \mathrm{a}$ & $10.1 \pm 4.5 \mathrm{a}$ & $73.7 \pm 6.8 b$ & $F=33.9, P<0.001$ & $r=0.77, P<0.001$ \\
\hline Metabolic rate (RR) & $\mathrm{mg} \mathrm{O}_{2} / \mathrm{h}$ & $1.28 \pm 0.13 \mathrm{a}$ & $1.54 \pm 0.17 \mathrm{ab}$ & $1.20 \pm 0.13 \mathrm{a}$ & $1.69 \pm 0.15 b$ & $F=5.1, P=0.004$ & \\
\hline
\end{tabular}


agonistic behaviours strongly increased during exposure to the mirror image (see Table I). All agonistic behaviours were positively correlated $(r>0.52, n=17, P<0.05)$, except for aggression with gill cover erection and for tail beating display with dorsal spread display $(r=0.22,0.43$, respectively, $n=17$, ns).

Oxygen consumption was significantly increased during exposure to the mirror image (Table I). Oxygen consumption tended to increase during exposure to the neutral stimulus, but this increase was not statistically significant (see Table I, before vs. during neutral stimulus).

To analyse the relationship between agonistic behaviour and metabolic rates, we selected the data that were collected during the mirror trial. A positive correlation was found between oxygen consumption and total agonistic behaviour, dorsal spread display, gill cover erection, and tail beating display (Table I: $r=0.77,0.69,0.65$, and 0.60 , respectively). No significant correlation was found for biting (Table I).

\section{Experiment II: Winner-Loser Effect}

Winners in comparison with losers spent nearly twice as much time during the experiment with gill cover erected and dorsal spread display (Table II). However, the values were rather low in comparison to those found in experiment I (Tables I and II). This is consistent with our expectation that natural fights are resolved without escalation.

Winners did not significantly differ in LRR measured during the night before the fighting, and no significant difference was found in the metabolic rates measured during fighting (Table II). However, the average routine metabolism measured over the day of fighting was significantly higher in winners than in losers (Table II, $P<0.05$ ).

Interestingly, LRR after fighting increased significantly in both winners and losers (matched sample $t$-test: winners, $t(6)=4.71, P=0.003$; losers, $t(6)=2.98, P=0.024)$, but the increase in LRR was higher in winners than in losers (matched sample $t$-test: LRR day $2-$ day $1, t(6)=2.47, P=0.049)$.

\section{DISCUSSION}

Lowest RR were selected from measurements taken during the dark period and therefore without interference of social stimulation or disturbances. The average level of routine metabolism obtained by this method was $0.36 \mathrm{mg} \mathrm{O}_{2} / \mathrm{h}$. Routine metabolism during the day was about two times as high as this level. Levels of routine metabolism for fish of about $2 \mathrm{~g}$ range from 0.1 to $1 \mathrm{mg} \mathrm{O}_{2} / \mathrm{h}$ [see Froese and Pauly, 2003]. Extrapolation of the relationship found between RR and body mass for Polyacanthus fasciatus, which is a species of the family Osphronemidae to which $B$. splendens also belongs, resulted in a value of $0.6 \mathrm{mg} \mathrm{O}_{2} / \mathrm{h}$ for an individual of $1.9 \mathrm{~g}$, which is close to the levels we found.

During fighting, metabolic rates increased to levels of about $1.8 \mathrm{mg} \mathrm{O}_{2} / \mathrm{h}$, which is a five-fold increase in comparison to the lowest level measured. A five-fold increase of basal metabolism is considered the maximum workload that organisms can sustain [Drent and Daan, 1980]. This suggests that the signalling behaviour shown by the fish during fighting was energetically costly. High cost of fighting was predicted for this species in order to explain why cheating by showing exaggerated levels of aggressive behaviour does not pay off [Halperin

TABLE II. Differences Between Winner and Losers of Betta splendens in Aggressive Behaviour and Oxygen Consumption

\begin{tabular}{|c|c|c|c|c|c|c|}
\hline & \multicolumn{2}{|c|}{ Display (time\%) day 2} & \multicolumn{4}{|c|}{ Metabolic rate $\left(\mathrm{mgO}_{2} / \mathrm{h}\right)$} \\
\hline & $\begin{array}{l}\text { Gill cover } \\
\text { erection }\end{array}$ & Dorsal spread & LRR night 1 & Fighting day 2 & Average day 2 & LRR night 2 \\
\hline Winner & $14.8 \pm 1.6 \%$ & $21.0 \pm 2.1 \%$ & $0.37 \pm 0.04$ & $1.84 \pm 0.10$ & $0.67 \pm 0.07$ & $0.53 \pm 0.06$ \\
\hline Loser & $8.7 \pm 2.0 \%$ & $13.8 \pm 2.7 \%$ & $0.35 \pm 0.06$ & $1.65 \pm 0.12$ & $0.57 \pm 0.09$ & $0.45 \pm 0.07$ \\
\hline \multirow[t]{2}{*}{$t$-test, $\mathrm{df}=6$} & $t=4.20, P<0.01$ & $t=2.53, P=0.045$ & $t=0.81, \mathrm{~ns}$ & $t=1.04, \mathrm{~ns}$ & $t=3.10, P=0.021$ & $t=2.53, P=0.045$ \\
\hline & \multicolumn{6}{|c|}{ Difference winner-loser } \\
\hline Dyad 1 & $11 \%$ & $23 \%$ & 0.10 & 0.65 & 0.25 & 0.16 \\
\hline Dyad 2 & $9 \%$ & $9 \%$ & 0.05 & 0.13 & 0.15 & 0.13 \\
\hline Dyad 3 & $8 \%$ & $6 \%$ & 0.10 & -0.52 & 0.05 & 0.05 \\
\hline Dyad 4 & $7 \%$ & $6 \%$ & -0.11 & 0.88 & 0.14 & 0.07 \\
\hline Dyad 5 & $6 \%$ & $5 \%$ & 0.02 & -0.05 & 0.01 & 0.14 \\
\hline Dyad 6 & $1 \%$ & $1 \%$ & -0.11 & 0.42 & 0.03 & -0.09 \\
\hline Dyad 7 & $1 \%$ & $0 \%$ & 0.09 & -0.16 & 0.08 & 0.15 \\
\hline Discarded & 0.05 & -0.16 & -0.19 & 0.14 & -0.04 & -0.04 \\
\hline
\end{tabular}


et al., 1998]. However, during fighting winners did not differ significantly from losers in energy expenditure. Only after the fight, winners showed higher routine metabolism than losers.

In experiment II, lowest levels of routine metabolism increased in winners from the night before fighting to after fighting. This difference between winners and losers is in concordance with studies that reported higher levels of basal metabolic rates in dominant animals as compared to subordinate animals (Acanthemblemaria spinosa e A. aspera, Clarke, 1992; Salmo salar, Metcalfe et al., 1995; Onchorhyncus masou, Yamamoto et al., 1998; and Salvelinus alpinus, Cutts et al., 2001]. Haller and Wittenberger [1988] showed that in fighting $B$. splendens males, carbohydrate degradation reached very high values after a short social contact. They concluded that winners were able to produce more energy per unit time than losers. Furthermore, Haller [1991] showed that after a fight, glycogen stores were degraded in fasted $B$. splendens. Similar results have been found by Neat et al. [1998] for tilapia who showed a depletion of energy stores and the accumulation of lactate due to anaerobic metabolism in muscles after fighting. Restoration of energy stores and metabolism of the lactates might result in some increase in metabolism after fighting. However, such restoration processes are likely in the range of hours, and therefore not likely to affect basal metabolism.

Longer lasting metabolic changes might be a consequence of the anabolic action of sex steroids, in particular, androgens. Androgens have been shown to correlate positively with basal metabolism [Ros et al., 2004; see also Buchanan et al., 2001; Wikelski et al., 1999], and the level of androgens increases in fish after exposure to an agonistic stimulus [Hirschenhauser et al., 2004]. Interestingly, RR after fighting and lowest levels of routine metabolism increased more in winners than in losers. This might reflect differences in winners and losers in the reactivity of the hypothalamus-pituitary-gonadal (HPG) axis. A possible function of an increase in metabolism after winning is that this plays a role in preparing the winner for subsequent challenges. This is relevant since bystander $B$. splendens males are known to eavesdrop on competing males, and subsequently to use the information about who won or lost to adjust their fighting tactic with these males [McGregor et al., 2001; Oliveira et al., 1998]. Higher aggressive reactivity in winning males might correct for the information asymmetry that is generated by eavesdropping.

The two primary agonistic displays, gill cover erection, and dorsal spread, were strongly positively correlated with energy metabolism. However, because we did not measure activity we cannot rule out that this increase in metabolism with agonistic display was a consequence of an increase in swimming activity in subjects that were more aggressive. Anyway, the expression of the displays might be used as a signal of energy expenditure in communication. Males showed these displays and the correlated high metabolic rates although they did not have direct physical contact with an opponent. Apparently, communicating about the potential to persist in display has benefits for the sender. One possibility is that showing displays correlated with metabolic costs will lead to a "war of attrition" between the opponents [Caryl, 1979], which has the potential to settle the conflict without incurring the damage resulting from an escalated fight. Damage may be especially detrimental in light of further agonistic interactions within the natural social context [McGregor, 1993; McGregor et al., 2001].

An increase in metabolism in fish that were exposed to a mirror was found by Wirtz and Davenport [1976] for Blennius pholis, but behavioural changes were not quantified in this study. In the mirror experiment, males exposed to the neutral stimulus still showed an increase in metabolism. Simpson [1968] showed that B. splendens tends to increase its exploratory movements when faced with a new object in the environment. The partitions we used as neutral stimulus and to socially isolate the males did show some reflection, to which the males might have responded. We did not have activity measurements to describe this exploratory behaviour and evaluate its costs.

Free-living animals show considerable individual variation in competitive tactics. Laboratory studies are necessary to test hypotheses about the physiological mechanisms that might explain this individual variation. Our study is in concordance with the general quoted assumption that high competitiveness in agonistic interactions is at the expense of high costs in terms of energy metabolism. The study further shows that fighting has long-lasting effects on metabolism. This suggests that in $B$. splendens fighting has physiological consequences for subsequent interactions.

\section{ACKNOWLEDGMENTS}

The authors are grateful to Peter Lawrence who constructed the respiratory system. RFO kindly provided the facilities for a sabbatical leave of KB. This work is based on a master thesis of $\mathrm{NC}$ at the 
Universidad de Lisboa. The manuscript has benefited from the help and discussions of Henrique Cabral during the master thesis, and from the comments of two anonymous referees. KB was funded by a VW-Foundation grant, which also provided an assistant fellowship for AFHR to work within the scope of this grant. This study is part of a research grant funded to RFO by the Portuguese Foundation for Science and Technology-FCT (POCTI/BSE/38484/01). RFO's research is also supported by the Plurianual Program of FCT (R\&D Unit 331/94). Procedures involving animals are in compliance with the current laws of Portugal.

\section{REFERENCES}

Baerends GP, Baerends-van-Roon JM. 1950. An introduction to the study of the ethology of cichlid fishes. Behaviour 1:S1-S242.

Bradbury JW, Vehrencamp SL (eds). 1998. "Principles of Animal Communication," Sunderland, MA: Sinauer Associates, Inc.

Buchanan KL, Evans MR, Goldsmith AR, Bryant DM, Rowe LV. 2001. Testosterone influences basal metabolic rate in male house sparrows: A new cost of dominance signaling? Proc R Soc Lond B Biol 268:1337-1344.

Caryl PG. 1979. Communication by agonistic displays: What can game theory contribute to ethology? Behaviour 68:136-161.

Cech JC, Jr. 1990. Respirometry. In: Schreck CB, Moyle PB (eds): "Methods for Fish Biology," Bethesda, MD: American Fisheries Society, pp 335-362.

Clarke RD. 1992. Effects of microhabitat and metabolic rate on food intake, growth and fecundity of two competing coral reef fishes. Coral Reefs 11:199-205.

Cutts CJ, Adams CE, Campbell A. 2001. Stability of physiological and behavioural determinants of performance in Arctic char (Salvelinus alpinus L.). Can J Fish Aquat Sci 58:961-968.

Dore F, Lefebre L, Ducharme R. 1978. Threat displays in Betta splendens: Effects of water condition and type of agonistic stimulation. Anim Behav 26:738-745.

Drent RH, Daan S. 1980. The prudent parent: Energetic adjustments in avian breeding. Ardea 68:225-252.

Enquist M, Leimar O, Ljungberg T, Mallner Y, Segerdahl N. 1990. A test of the sequential assessment game: Fighting in the cichlid fish, Nannacara anomala. Anim Behav 47:387-410.

Evans CS. 1985. Display vigor and subsequent fight performance in the Siamese fighting fish, Betta splendens. Behav Process 11:113-122.

Froese R, Pauly D (eds): 2003. FishBase. World Wide Web Electronic Publication. www.fishbase.org, version 06 January 2004.

Gallup GG, Jr. 1968. Mirror-image stimulation. Psychol Bull 70: 782-793.

Grafen A. 1990. biological signals as handicaps. J Theor Biol 144: $517-546$.

Grantner A, Taborsky M. 1998. The metabolic rates associated with resting, and with the performance of agonistic, submissive and digging behaviours in the cichlid fish Neolamprologus pulcher (Pisces: Cichlidae). J Comp Physiol B 168:427-433.

Haller J. 1991. Biochemical cost of a fight in fed and fasted Betta splendens. Physiol Behav 49:79-82.

Haller J, Wittenberger C. 1988. Biochemical energetics of hierarchy formation in Betta splendens. Physiol Behav 43:447-450.
Halperin JRP, Giri T, Elliott J, Dunham DW. 1998. Consequences of hyper-aggressiveness in Siamese fighting fish: Cheaters seldom prospered. Anim Behav 55:87-96

Hirschenhauser K, Taborsky M, Oliveira T, Canario AVM, Oliveira RF. 2004. A test of the 'challenge hypothesis' in cichlid fish: Simulated partner and territory intruder experiments. Anim Behav 68:741-750.

Huntingford FA, Taylor AC, Sneddon LU, Neat FC. 2000. Prowess and the resolution of animal fights. In: Espmark Y, Amundsen T, Roseqvist G (eds): "Animal Signals: Signalling and Signal Design in Animal Communication," Trondheim, Norway: Tapir Academic Press, pp 259-276.

Johnson RN, Johnson LD. 1973. Intra- and interspecific social and aggressive behaviour in the Siamese fighting fish, Betta splendens. Anim Behav 21:665-672.

Maan ME, Groothuis TGG, Wittenberg J. 2001. Escalated fighting despite predictors of conflict outcome: Solving the paradox in a South American cichlid fish. Anim Behav 62:623-634.

Maynard-Smith J (ed): 1982. "Evolution and the Theory of Games," Cambridge,MA: Cambridge University Press.

McGregor PK. 1993. Signalling in territorial systems: A context for individual identification, ranging and eavesdropping. Philos Trans R Soc B 340:237-244.

McGregor PK, Peake TM, Lampe HM. 2001. Fighting fish Betta splendens extract relative information from apparent interactions: What happens when what you see isn't what you get. Anim Behav 62:1059-1065.

Meliska CJ, Meliska JA. 1980. The relationship of the mirror-elicited display to combat behaviors in Betta splendens. Behav Neural Biol 30:207-217.

Metcalfe NB, Taylor AC, Thorpe JE. 1995. Metabolic rate, social status and life-history strategies in Atlantic salmon. Anim Behav 49:431-436.

Neat FC, Taylor AC, Huntingford FA. 1998. Proximate costs of fighting in male cichlid fish: The role of injuries and energy metabolism. Anim Behav 55:875-882.

Oliveira RF, McGregor PK, Latruffe C. 1998. Know thine enemy: Fighting fish gather information from observing conspecific interactions. Proc R Soc Lond B Biol 265:1045-1049.

Parker GA. 1974. Assessment strategy and the evolution of fighting behaviour. J Theor Biol 47:223-243.

Ros AFH, Becker K, Canário AVM, Oliveira RF. 2004. Androgen levels and energy metabolism in the Mozambique tilapia, Oreochromis mossambicus. J Fish Biol 65:895-905.

Simpson MJA. 1968. The display of the Siamese fighting fish Betta splendens. Anim Behav Monogr 1:1-73.

Számado S. 2003. Threat displays are not handicaps. J Theor Biol 221, 327-348.

Thompson T. 1966. Operant and classically-conditioned aggressive behavior in Siamese fighting fish. Am Zool 6:629-641.

Wikelski M, Lynn S, Breumer C, Wingfield JC, Kenagy GJ. 1999. Energy metabolism, testosterone and corticosterone in whitecrowned sparrows. J Comp Physiol A 185:463-470.

Wirtz P, Davenport J. 1976. Increased oxygen consumption in blennies (Blenius pholis L.) exposed to their mirror image. J Fish Biol 9:67-74.

Yamamoto T, Ueda H, Higashi S. 1998. Correlation among dominance, metabolic rate and otolith size in masu salmon. J Fish Biol 52:281-290.

Zahavi A. 1977. Reliability in communication systems and the evolution of altruism. In: Stonehouse B, Perrins CM (ed): "Evolutionary Ecology," London: Macmillan Press, pp 253-259. 